Journal of Behavioral Decision Making

J. Behav. Dec. Making, 18: 187-198 (2005)

Published online in Wiley InterScience

(www.interscience.wiley.com). DOI: 10.1002/bdm.494

\title{
Profit Maximization versus Disadvantageous Inequality: The Impact of Self-Categorization
}

\author{
STEPHEN M. GARCIA ${ }^{1} *$, AVISHALOM TOR ${ }^{2}$, MAX H. BAZERMAN ${ }^{3}$ \\ and DALE T. MILLER ${ }^{4}$ \\ ${ }^{1}$ University of Michigan, USA \\ ${ }^{2}$ Haifa University Faculty of Law, Israel \\ ${ }^{3}$ Harvard University, USA \\ ${ }^{4}$ Stanford University, USA
}

\begin{abstract}
Choice behavior researchers (e.g., Bazerman, Loewenstein, \& White, 1992) have found that individuals tend to choose a more lucrative but disadvantageously unequal payoff (e.g., self - \$600/other - \$800) over a less profitable but equal one (e.g., self $-\$ 500 /$ other-\$500); greater profit trumps interpersonal social comparison concerns in the choice setting. We suggest, however, that self-categorization (e.g., Hogg, 2000) can shift interpersonal social comparison concerns to the intergroup level and make trading disadvantageous inequality for greater profit more difficult. Studies 1-3 show that profit maximization diminishes when recipients belong to different social categories (e.g., genders, universities). Study 2 further implicates self-categorization, as selfcategorized individuals tend to forgo profit whether making a choice for themselves or another ingroup member. Study 3, moreover, reveals that social categorization alone is not sufficient to diminish profit maximization; individuals must self-categorize and identify with their categorization. Copyright (C) 2005 John Wiley \& Sons, Ltd.
\end{abstract}

KEY WORDS choice; decision making; self-categorization; fairness; trade-offs; profit maximization; social identity; social comparison

\section{INTRODUCTION}

Although most people prefer having more money to less, numerous studies at the intersection of experimental economics and psychology have demonstrated that individuals do not always maximize profit (e.g., Guth, Schmittberger, \& Schwarz, 1982; Pillutla \& Murnighan, 1996; Roth, 1995). One research stream in

\footnotetext{
* Correspondence to: Stephen M. Garcia, University of Michigan, Gerald R. Ford School of Public Policy, Ann Arbor, MI 48109-1220, USA. E-mail: smgarcia@umich.edu

Contract/grant sponsors: Center for Local, State, and Urban Policy, University of Michigan, USA; Program on Negotiation, Harvard Law School, USA; Olin Center for Law, Economics, and Business, Harvard Law School, USA.
} 
particular has uncovered situations in which the social comparison process prevents individuals from maximizing profit (Adams, 1963; Loewenstein, Thompson, \& Bazerman, 1989). Subsequent research (Bazerman, Loewenstein, \& White, 1992; Bazerman, White, \& Loewenstein, 1995; Blount \& Bazerman, 1996; Bazerman, Schroth, Shah, Diekmann, \& Tenbrunsel, 1994; Hsee, Loewenstein, Blount, \& Bazerman, 1999) has qualified this finding, however, by demonstrating that the method of elicitation can shape preferences for profit maximization in the face of social comparison concerns. For example, when payoffs are presented separately, between-subjects, individuals rate a payoff in which they and a counterpart both earn $\$ 500$ more highly than individuals who rate a payoff in which they earn $\$ 600$ and their counterpart earns $\$ 800$. However, when individuals are given the opportunity simultaneously to compare alternative payoff allocations in a choice setting, they tend to choose the more lucrative payoff. Hence, profit maximization trumps interpersonal social comparison concerns in the choice setting.

The present analysis suggests that this tendency to maximize profit in the choice setting is significantly diminished when payoff recipients belong to different social categories (e.g., genders, countries, almamaters, etc.). In these cases, individuals self-categorize themselves in terms of their social category memberships (Hogg, 2000), and social comparison concerns shift from the interpersonal level, between two individuals, to the intergroup level, between groups. While additional profit is sufficient to overcome interpersonal social comparison concerns in the choice setting (Bazerman et al., 1992; Bazerman et al., 1995; Blount \& Bazerman, 1996), we predict that self-categorized individuals will increasingly forgo profit maximization even in a transparent choice setting. Thus, when payoffs are allocated to members of different social category groups, individuals often tend not to maximize profit, choosing instead a less lucrative but equal allocation. Accordingly, we propose that self-categorization is an important factor that can make a tradeoff between profit and disadvantageous inequality more difficult.

\section{Social comparison and choice behavior}

Harnessing social comparison theory (Festinger, 1954), Messick and Sentis (1985) distinguished between nonsocial utility (i.e., payment to oneself in absolute profit) and social utility (i.e., payment to oneself relative to the payment of another individual). Building on this background, Loewenstein et al. (1989) found that individual social-utility functions are non-linear and that the form of an individual's utility function depends on a number of factors. Loewenstein et al. (1989) placed subjects in a situation characterized by a strong equality norm and asked them to assess their satisfaction with different monetary outcomes for themselves and for another person in a number of fictional disputes. Interpersonal comparisons overwhelmed the concern for personal outcomes. For example, in between-subjects conditions, participants rated the outcome of $\$ 500$ for oneself and $\$ 500$ for the other person as more satisfactory than the outcome of $\$ 600$ for oneself and $\$ 800$ for the other person, revealing a preference for equal outcomes with less money over unequal outcomes with more. Hence, in the abstract, social comparison concerns make a lucrative but disadvantageously unequal payoff seem unattractive.

Researchers have begun to clarify the cognitive and informational variables that affect this phenomenon, and one interesting revelation has been that presenting these payoff options side-by-side in a choice setting assuages social comparison concerns and facilitates profit maximization. For example, Bazerman et al. (1992) showed that, when individuals evaluated payoffs in a choice setting, they maximized personal profit by choosing the $\$ 600$ - self $/ \$ 800$ - other option over the $\$ 500$ - self $/ \$ 500$ - other option. Blount and Bazerman (1996) extended this result to a situation involving real payoffs. One group of potential participants in an experiment was offered $\$ 7$ to participate in a 40-minute experiment, knowing that all participants would receive $\$ 7$. A second group was offered $\$ 8$ to participate in a 40-minute experiment, knowing that some participants were arbitrarily (based on a random factor) offered $\$ 10$. A third group was given a choice: (1) to participate in a 40-minute experiment in which everyone would be paid $\$ 7$; (2) to participate in a 40minute experiment in which some participants, including themselves, would receive $\$ 8$ and others would 
receive $\$ 10$; or (3) not to participate. Although significantly more participants in the first group chose to participate than in the second group, the majority of participants in the choice condition chose to participate in the experiment that gave them $\$ 8$ and others $\$ 10$.

In the choice setting, individuals can use the two alternative options as points of reference that enable them to recognize the tradeoff between social comparison concerns and sheer profit. As Bazerman et al. (1992) suggest, "In a choice task, the subject evaluating the two outcomes from our earlier example simultaneously might reason, 'Surely it is worth $\$ 200$ in inequality to receive an extra $\$ 100$ '”(p. 222). This analysis suggests that, although making less money relative to a counterpart is painful, individuals willingly suffer the pain of social comparison in return for higher financial profits in these interpersonal situations.

\section{The impact of self-categorization}

Does the apparent benefit of higher monetary profits always trump the social comparison concerns in the choice setting? Certainly, factors that amplify the concern for social comparison will lead individuals knowingly to forgo profit in order to satisfy social comparison concerns. We assert that self-categorization (Hogg \& Abrams, 1990; Turner, Hogg, Oakes, Reicher, \& Wetherell, 1987) is one factor that can shift the concern for social comparison from the interpersonal level to the intergroup level and diminish the tendency to maximize profit in the choice setting.

Self-categorization theory (Hogg \& Abrams, 1990; Turner et al., 1987) emphasizes the cognitive aspects of social identity theory (Deaux, 1996; Tajfel, 1981; Turner, 1982) and describes how individuals categorize themselves into ascribed, chosen, or arbitrary social categories. For example, upon arriving in London, we might categorize ourselves as "Americans" and those around us as "Britons." Individuals who selfcategorize and identify with that categorization will then demonstrate intergroup biases such as ingroup favoritism. Uncertainty reduction (Hogg \& Mullin, 1999; Mullin \& Hogg, 1998) and self-esteem (Abrams \& Hogg, 1988; Tajfel, 1981) are considered primary motives for self-categorization, and self-categorization relies on the social comparison process to fulfill these two motives (Hogg, 2000; Turner 1975).

The uncertainty reduction model of self-categorization (Hogg \& Mullin, 1999) emphasizes the self-evaluation motive, an epistemic motivation to reduce uncertainty, and researchers posit that individuals experiencing uncertainty will use self-categorization as a way to reduce the uncertainty. For example, participants in minimal group experiments self-categorize and identify with their arbitrarily assigned group (e.g., "Red Team") because of the situational uncertainty of these experiments; participants do not know what is expected of them during the experiment, and so they self-categorize and identify with other "Red Team" members and exhibit ingroup favoritism vis-à-vis "Blue Team" members. For instance, "Red Team" members might rate their own ingroup in ways that favorably distinguish themselves from "Blue Team" members (e.g., Oaker \& Brown, 1986; Turner, Brown, \& Tajfel, 1979). Self-categorization reduces uncertainty because the social comparison process enables ingroup members to maintain the distinctiveness of the ingroup (Hogg, 2000).

Yet this motive to reduce uncertainty may also work "in conjunction with the self-enhancement and selfesteem motives" (Hogg, 2001, p. 339). The social comparison process also enables ingroup members to pursue self-enhancement in ways that "accentuate differences that evaluatively favor the in-group" (Hogg, 2000) and protect the positive valence of their social identity with respect to the outgroup (Hogg, 2000). Hence, intergroup social comparisons emerge with self-categorization and precipitate ingroup favoritism and behaviors that ensure or protect the ingroup's distinctiveness or positive valence over the outgroup.

Since the social comparison process enables self-categorized individuals to reduce uncertainty and boost self-esteem, we can predict that trading disadvantageous inequality for additional profit will be more difficult for self-categorized individuals. In the original Bazerman et al. $(1992,1995)$ studies, individuals recognized the pain associated with upward social comparison in the choice setting, but nevertheless preferred to maximize profit. For self-categorized individuals, however, this tradeoff should be more difficult because selfcategorization shifts social comparison concerns from the interpersonal level, between individuals, to the 
intergroup level, between groups. Accepting less profit relative to the outgroup would pose a threat to ingroup members, as social comparison processes would no longer enable self-categorized individuals to protect the distinctiveness or positive valence of the ingroup. Because such threats can lead to uncertainty and jeopardize self-esteem (e.g., Gaertner, Sedikides, \& Graetz, 1999; Hogg, 2001), we predict that selfcategorized individuals will tend to choose the less lucrative equal payoff in the choice setting in order to avoid the threat posed by the disadvantageously inequality.

\section{Overview}

The goal of the present analysis was to examine how self-categorization could diminish the tendency to maximize profit in choice behavior. On a broader level, this analysis sought to bridge the self-categorization and decision-making literatures. We induced self-categorization by allocating payoffs across social category lines and asked participants to choose whether the ingroup would receive the same payoff as the outgroup or a more lucrative but disadvantageously unequal one.

\section{STUDY 1: SELF-CATEGORIZATION}

We tested the prediction that self-categorized individuals would be less willing to tradeoff disadvantageous inequality for profit relative to a control condition. We took advantage of gender as a naturally occurring social category.

\section{Participants}

Forty-four University of Michigan undergraduates volunteered to participate in a brief questionnaire study. Participants were recruited at campus student centers.

\section{Procedure}

In a between-subjects design, participants were assigned to either a mixed-gender condition (self-categorization condition) or gender-neutral condition (control condition). The self-categorization condition read as follows: "Imagine you agreed to participate in only one of the following experiments. Which experiment would you participate in? (indicate Experiment 1 or 2)." At this point female participants saw descriptions of Experiment 1 and 2, respectively: "Experiment 1: This experiment requires two minutes to complete. It is a study on attitudes toward campus issues. Female and male participants are paid \$1.00; Experiment 2: This experiment requires three minutes to complete. It is a study on game theory. Female participants are paid $\$ 2.00$; Male participants are paid $\$ 5.00$. (Note: These arbitrary differences in pay were based on a coin toss)." Male participants read slightly different descriptions of Experiment 1 and 2, respectively: "Male and female participants are paid \$1.00" and "Males participants are paid \$2.00; Female participants are paid \$5.00."

The control condition was identical but with modified payoffs for Experiment 1 and 2, respectively: "All participants are paid \$1.00" and "Half the participants (including yourself) are paid \$2.00; Half the participants are paid \$5.00." We likewise noted that the arbitrary differences in pay were based on a coin toss.

\section{Results and discussion}

Results from a chi-square analysis revealed a significant effect in the predicted direction, $\chi^{2}(d f=1$, $N=44)=6.56, p<0.05$. Only $62 \%$ of the participants in the self-categorization condition $(n=24)$ chose 
Experiment 2 and maximized profit, whereas $95 \%$ of the participants in the control condition $(n=20)$ were willing to trade disadvantageous inequality for extra profit. Moreover, there were no apparent gender differences $(p<0.20)$ in the tendency to forgo profit in the self-categorization condition.

In line with previous research, these results reveal that in the absence of self-categorization, the utility of earning a greater profit trumps social comparison concerns in the choice setting (Bazerman et al., 1992). However, when allocation recipients belong to different social categories, the self-categorization process shifts the concern for social comparison from the interpersonal level to the intergroup level (Hogg, 2000). Because intergroup comparisons function to monitor and protect the distinctiveness of the ingroup, the self-categorized individual tends to avoid the threatening disadvantageous inequality. Although there is a strong tendency to accept a more lucrative but lesser dollar amount compared to other individuals, it becomes especially difficult for the self-categorized individual when these other individuals are outgroup members.

While social comparison can explain these dynamics, an alternative explanation might be that it is simply "unfair" to pay one social category more than another. For instance, some might argue that the coin toss was somehow systematically biased or that people did not maximize profit because of fairness concerns (e.g., Rabin, 1993) or insult (e.g., Pillutla \& Murnighan, 1996). We did note, however, that the differences in pay were based on the arbitrary toss of a coin, which not only avoids the possible perception of discrimination against a given social category, but was also found sufficiently non-aversive in the control condition to allow almost all participants to maximize profits in the face of disadvantageous inequality. Study 2 used logistical reasons to justify differences in payoff discrepancies and probed for additional evidence of the self-categorization process.

\section{STUDY 2: SELF-CATEGORIZATION AND DEPERSONALIZATION}

To examine further whether the self-categorization process impeded profit maximization in the choice setting, we explored whether self-categorized individuals would also forgo profit maximization when they made a choice for another ingroup member. One consequence of self-categorization involves depersonalization (Hogg, Cooper-Shaw, \& Holzworth, 1993; Hogg \& Haines, 1996). Self-categorization depersonalizes "perception and conduct such that members, including oneself, are not processed as complex, multidimensional whole persons but, rather, as embodiments of the perceived group prototype" (Hogg et al., 1993, p. 453). The ingroup prototype itself is "an integrated, abstract representation of specific stereotypical/normative characteristics that defines ingroup" (Hogg et al., 1993, p. 464). Self-categorized individuals, in their depersonalized state, thus behave, perceive, and make decisions in ways that are consistent with the ingroup prototype. For this reason, self-categorized individuals should make the same payoff decision for another ingroup member as they would make for themselves. Study 2 tested the prediction that self-categorization would attenuate profit maximizing tendencies whether self-categorized individuals made a decision for themselves or another ingroup member.

\section{Participants}

A total of 168 undergraduates at University of Michigan participated in a between-subjects design study. Participants were recruited via e-mail for an online survey.

\section{Procedure}

After being assigned to one of four conditions, participants were asked to choose between two hotel arrangements. The self-categorization condition read as follows, "Imagine that you are on an 
all-expense-paid weekend trip with two groups of students from the University of Michigan and Harvard, and there are vacancy issues. One option is to have everyone stay at a 1-star motel. Because the UM group is slightly larger, another option is to have the UM group stay at a somewhat better 2-star hotel and the Harvard group at an even better 4-star hotel. In either case, both groups will not be interacting." At this point, participants read, "If asked to choose, which option would you select?" and then chose between "Option A: All Michigan and Harvard students stay at the 1-star motel" and "Option B: Michigan students stay at the 2-star hotel; Harvard students stay at the 4-star hotel." In the self-categorization-other condition, participants made the identical choice but for another ingroup member: "Imagine that two groups of students from the University of Michigan and Harvard are on an all-expense-paid weekend trip . If asked to choose for a fellow Michigan student, which option would you select?"

The control condition was identical but asked participants to imagine they were traveling with another group from the University of Michigan, and the choice was between "All Michigan students stay at the 1-star motel" and "Half the Michigan students (including yourself) stay at the 2-star hotel; Half the Michigan students stay at the 4-star hotel." We also included a secondary control condition to reflect the original interpersonal choice context (e.g., Bazerman et al., 1992): "Imagine that you and another student are on an all-expense-paid weekend trip ..." Because the differences in hotels in all the other conditions was based on logistical reasons (e.g., "slightly larger group"), the secondary control condition accordingly attributed the differences to "logistical reasons."

\section{RESULTS AND DISCUSSION}

To test the prediction that individuals become less willing to maximize profit in the self-categorization $(n=44)$ and self-categorization-other conditions $(n=37)$ relative to the control $(n=40)$ and secondary control conditions $(n=47)$, we assigned the following contrast weights (see Rosenthal \& Rosnow, 1991): 1(self-categorization condition), 1(self-categorization-other condition), -1(control condition), and -1 (secondary control condition). We then performed a binary logistic regression on choice $(1=$ Option A, $2=$ Option B). A significant pattern confirmed the contrast $(b=-0.36$, Wald $=5.1, p<0.05)$. See Table 1.

These results further implicate the role of self-categorization. Only 55\% in the self-categorization and $49 \%$ in the self-categorization-other conditions maximized the quality of their own hotel, compared to $68 \%$ in the control and $70 \%$ in the secondary control conditions. Finally, because the selfcategorization and self-categorization-other conditions were not statistically different $(p>0.73)$, the implication is that self-categorization underlies this effect. More specifically, to the extent that self-categorization leads to depersonalization, self-categorized individuals should make the same decision both for themselves and another ingroup member. Hence, these results are consistent with self-categorization theory.

Table 1. Percent and count choosing the 2-star/4-star hotel over the 1-star motel by condition

\begin{tabular}{lcc}
\hline Condition & $\%$ & Count $(n)$ \\
\hline Self-categorization & 54.5 & $24(44)$ \\
Self-categorization - other & 48.6 & $18(37)$ \\
Control & 67.5 & $27(40)$ \\
Secondary control & 70.2 & $33(47)$ \\
\hline
\end{tabular}




\section{STUDY 3: SELF-CATEGORIZATION AND IDENTIFICATION}

While Study 2 suggested that self-categorized individuals were interchangeable with other ingroup members and consequently made similar decisions for themselves and other ingroup members, Study 3 sought further to underscore the impact of self-categorization by examining the role of social identification. Social categorization alone is not sufficient to precipitate intergroup phenomena; individuals must self-categorize and identify with the particular social category (Grieve \& Hogg, 1999). To illustrate this point, Study 3 measured social identification with respect to the decision to forgo profit. Individuals who self-categorize and identify with the focal social category should be less willing to maximize profit in the inter-category context, compared to individuals who do not.

To test this prediction, we used a business strategy scenario: a choice between a joint venture that increases revenue by $10 \%$ for each party and a joint venture that increases revenue by $15 \%$ for the ingroup and $20 \%$ for the outgroup. We compared a joint venture between an American firm and a foreign firm (self-categorization condition) with a joint venture between two American firms (control condition). We also included a secondary control condition in which no social category was made salient. Our main prediction was that level of social identification with the United States of America would be associated with the decision to forgo profit in the self-categorization condition. Namely, individuals who chose to forgo profit would report higher levels of identification, compared to individuals who chose to maximize profit. We also predicted that individuals in the self-categorization condition would be overall less likely to maximize profit relative to the control and secondary control conditions and that the decision to maximize profit would be associated with the pain of social comparison.

\section{Participants}

A total of 166 undergraduate American citizens participated in a between-subjects design study. Participants were recruited to volunteer for a two-minute survey at various campus student centers.

\section{Procedure}

On the first page, participants read a scenario about a business joint venture. The self-categorization condition was about a joint venture between an American and a French airline: "Imagine that you work for American Airlines, and you are thinking about a possible joint venture with Air France. Profits will depend on the timeline of the joint venture, and it can only be one of the following two options: Option A: Short TermAmerican Airlines" profits will increase by $10 \%$ and Air France's profits will increase by 10\%; Option B: Long Term-American Airlines" profits will increase by 15\% and Air France's profits will increase by 20\%." Participants were then asked, "Of these two options, which one would you choose? (please check)."

The control condition was simply between two American firms-namely American Airlines and Delta Airlines. The secondary control condition, which was not be based on any group, was between two selfemployed pilots: "Imagine that you are a self-employed charter pilot, and you are thinking about a possible joint venture with another self-employed charter pilot." The payoffs were the same as the other two conditions, but worded as "your profits" versus "the other pilot's profits."

On the second page, participants were then reminded of Option B verbatim ("On the previous page, you saw Option B ..."), and then asked a question about the pain of social comparison, "In your opinion, how painless or painful would it be to choose Option B?" At this point, participants circled a value that ranged from -3("Painless") to 3("Painful"), with 0 as the midpoint.

On the third page, participants then responded to questions regarding identification with the United States of America: How much do you identify with other Americans? $(1=$ not very much, $7=$ very much); How much pride do you have in being an American? (1=not very much, $7=$ very much); How similar do you 
think you are to other Americans in terms of general attitudes and beliefs? $(1=$ not very similar, $7=$ very similar). These three questions became the measure of social identification.

\section{Results and discussion}

To test the prediction that individuals would be less willing to maximize profit in the self-categorization condition $(n=56)$ relative to the control $(n=64)$ and secondary control conditions $(n=46)$, we assigned the following contrast weights (see Rosenthal \& Rosnow, 1991): 2(self-categorization condition), -1(conition), and -1 (secondary control condition). We then performed a binary logistic regression on choice $(1=$ "10\%-10\%;" $2=$ "15\%-20\%") while controlling for administration sites, and the contrast was significant $(b=-35$, Wald $=7.5, p<0.01)$. See Table 2 . Only $55 \%$ of the participants maximized profit in the self-categorization condition compared to $73 \%$ of the participants in the control condition and $78 \%$ in the secondary control condition.

To test the prediction that individuals who select the less lucrative equal payoff option-would also tend to perceive the more lucrative option as being more painful to choose, we converted the $-3 / 3$ scale to a conventional seven-point scale and performed a $t$-test on the reported pain of choosing the lucrative but disadvantageously unequal payoff with choice as the independent variable. The $t$-test was significant $(t(154)=5.94, p<0.001)$. Individuals who chose the equal payoff $(M=4.30, S D=1.28)$ considered the lucrative payoff to be more painful than those who chose the lucrative payoff $(M=2.81, S D=1.50)$. The pain of social comparison is felt when forgoing profit.

These painfulness ratings may also provide a window onto why the individuals in the self-categorization condition a chose the equal payoffs. Self-categorized individuals may derogate outgroups, but they may also simply try to protect the ingroup (Hogg, 2000). Because those who chose to forgo profit considered the profitable alternative especially painful, it seems that the self-categorized individuals in this study were more concerned with protecting the ingroup, as opposed to pulling down the outgroup. This analysis resonates with other research that suggests that ingroup favoritism does not necessarily require a more negative response toward the outgroup (e.g., Brewer, 1979).

To illuminate further the impact of self-categorization processes, we tested the prediction that, in the selfcategorization condition, individuals who chose to forgo profit, relative to those who did not, would report significantly higher levels of social identification with the United States of America. We first averaged the three social identification items $(\alpha=0.79)$ to create a social identification index. We then conducted a $t$-test on the level of social identification by choice in the self-categorization condition. Indeed, those individuals in the self-categorization condition who chose to forgo profit reported significantly higher levels of social identification $(M=5.3, S D=1.47)$ than did those who maximized profit $(M=4.4, S D=1.38), t(53)=2.44$, $p<0.05$. As expected, there were no differences in social identification between those who chose to forgo profit and those who chose to maximize profit in either the control $(t(61)<1: M=4.9, S D=1.04$ vs. $M=4.7, S D=1.39)$ or the secondary control conditions $(t(43)<1: M=4.8, S D=1.04$ vs. $M=4.8$, $S D=1.12$ ).

These results suggest that social categorization alone is not sufficient to impede profit maximization tendencies. Individuals must self-categorize and identity with the social category membership at hand.

Table 2. Percent and count choosing the $15-20 \%$ over the $10-10 \%$ increase in profits by condition

\begin{tabular}{lcc}
\hline Condition & $\%$ & Count $(n)$ \\
\hline Self-categorization & 55.4 & $31(56)$ \\
Control & 73.4 & $47(64)$ \\
Secondary control & 78.3 & $36(46)$ \\
\hline
\end{tabular}


If individuals do not self-categorize and strongly identify with being an American, say, they will proceed to maximize profit. However, if individuals self-categorize and strongly identify with a category, such as being an American, then individuals will forgo profit maximization. Hence, the proposed effect will be prevalent among those who self-categorize and strongly identify with the focal social category and virtually nonexistent among those who do not.

\section{GENERAL DISCUSSION}

Previous research suggested that, in a choice setting, alternative payoff allocations provide individuals with alternative reference points, leading them to forgo social comparison concerns for profit maximization (Bazerman et al., 1992, 1994, 1995; Blount \& Bazerman, 1996). The present analysis, however, explored how self-categorization can attenuate this tradeoff by shifting social comparison concerns from the interpersonal level to the intergroup level. Self-categorized individuals experienced greater difficulty in trading disadvantageous inequality for profit, regardless of whether differences in payoffs were based on an arbitrary coin toss (Study 1), on objective logistical limitations (Study 2), or on market forces (Study 3). Studies 2 and 3 further implicated self-categorization by testing hypotheses based on the processes of depersonalization and social identification. Study 2 found that self-categorized individuals in their depersonalized state tended to forgo profit maximization, whether making decisions for themselves or another group member. Study 3 found that social categorization per se is not sufficient to impede profit maximization; individuals must also self-categorize and identify with the social category at hand.

\section{Implications and future directions}

The present analysis sheds new light on how members of organizations may react differently to payoff allocations depending on the social context at hand. When allocations are distributed in the absence of self-categorization, individuals will be more willing to choose profit maximization. If individuals selfcategorize, however, willingness to maximize profit may diminish in a choice setting that couples greater profit with disadvantageous inequality. Under these circumstances, "enlarging the pie" may be especially difficult for individuals who self-categorize themselves into social categories that are asked to make the tradeoff from a smaller but equal slice of the pie to a larger but disadvantageously unequal one.

The process of "recategorization," however, may help safeguard against unwanted self-categorizations. Recategorization, based on the "common ingroup identity model" (Gaertner, Dovidio, Anastasio, Bachman, \& Rust, 1993), is a process by which a larger, more inclusive, social category is made salient to foster trust and cooperation between groups from different social categories (Gaertner \& Dovidio, 2000). If Congressional Democrats and Republicans from the South, for instance, are competing for federal funds, the common ingroup identity model would suggest that trust and cooperation can be facilitated by making salient the fact that both groups belong to the same region. Thus, invoking the superordinate category of the "South" may precipitate self-categorizations as "Southerners" and, in turn, facilitate the acceptance of profitable but disparate allocations, increasing the social utility of such allocations together with their beneficial monetary consequences.

The present results may also have interesting implications for ultimatum games (e.g., Guth et al., 1982; Roth, 1995). Although the strategic, interdependent nature of the "take-it-or-leave-it" and "all-or-nothing" ultimatum offers is quite different from the payoffs presented in the choice sets of the present studies, selfcategorization may exert similar effects on the decision of whether to accept an ultimatum offer or not. For instance, individuals may exhibit an even greater tendency to reject an ultimatum offer, rather than accept a disadvantageously unequal offer, when the parties belong to different social categories (e.g., individuals from different countries) than when they belong to the same social category (e.g., individuals from the same 
country). It would also be interesting to examine whether individuals making ultimatum offers in intercategory contexts anticipate the reaction of the recipients and therefore exhibit a greater tendency toward equal splits than they would in the absence of self-categorization.

\section{Conclusion}

While previous research suggests that individuals tend to choose a lucrative but disadvantageously unequal payoff over a less lucrative but equal one in the choice setting (e.g., Bazerman et al., 1992), the present research suggests that self-categorization is one important factor that can shift the concern for social comparison from the interpersonal level to the intergroup level and attenuate profit-maximizing tendencies. Self-categorized individuals tend to forgo profit maximization, whether making a decision for themselves or another ingroup member. While this analysis illuminates the role of self-categorization in the tradeoff between profit and disadvantageous inequality, it also helps bridge the decision-making and selfcategorization literatures.

\section{ACKNOWLEDGEMENTS}

The authors wish to thank Bob Axelrod, Martha Feldman, Jim Hines, Daniel Kahneman, Ilana Ritov, Norbert Schwarz, and Kim Weaver for thoughtful comments on the paper. We also thank Elizabeth Brisson, Bryan Harrison, Brian Hartmann, Mitch Meyle, Alex Radetsky, Bryan Spence, and Irina Yudovich for assistance with data collection. This research was supported by a grant from the Center for Local, State, and Urban Policy at the University of Michigan.

\section{REFERENCES}

Abrams, D., \& Hogg, M. A. (1988). Comments on the motivational status of self-esteem in social identity and intergroup discrimination. European Journal of Social Psychology, 18, 317-334.

Adams, J. S. (1963). Toward an understanding of inequality. Journal of Abnormal and Social Psychology, 67, 422-436.

Bazerman, M. H., Loewenstein, G. F., \& White, S. B. (1992). Reversals of preference in allocation decisions: judging an alternative versus choosing among alternatives. Special Issue: process and outcome: perspectives on the distribution of rewards in organizations. Administrative Science Quarterly, 37, 220-240.

Bazerman, M. H., Schroth, H. A., Shah, P. P., Diekmann, K. A., \& Tenbrunsel, A. (1994). The inconsistent role of comparison others and procedural justice in reactions to hypothetical job descriptions: implications for job acceptance decisions. Organizational Behavior and Human Decision Processes, 60, 326-352.

Bazerman, M. H., White, S. B., \& Loewenstein, G. F. (1995). Perceptions of fairness in interpersonal and individual choice situations. Current Directions in Psychological Science, 4, 39-43.

Blount, S., \& Bazerman, M. H. (1996). The inconsistent evaluation of absolute versus comparative payoffs in labor supply and bargaining. Journal of Economic Behavior and Organization, 30, 227-240.

Brewer, M. B. (1979). In-group bias in the minimal intergroup situation: a cognitive-motivational analysis. Psychological Bulletin, 86, 307-324.

Deaux, K. (1996). Social identification. In E. T. Higgins, \& A. W. Kruglanski (Eds.), Social psychology: Handbook of basic principles (pp. 777-798). New York: Guilford Press.

Festinger, L. (1954). A theory of social comparison. Human Relations, 7, 117-140.

Gaertner, S. L., \& Dovidio, J. F. (2000). Reducing intergroup bias: The common ingroup identity model. Philadelphia, PA: Psychology Press/Taylor \& Francis.

Gaertner, S. L., Dovidio, J. F., Anastasio, P. A., Bachman, B. A., \& Rust, M. C. (1993). The common ingroup identity model: recategorization and the reduction of intergroup bias. In W. Stroebe, \& M. Hewstone (Eds.), European review of social psychology (Vol. 4, pp. 1-26). Chichester, UK: Wiley. 
Gaertner, L., Sedikides, C., \& Graetz, K. (1999). In search of self-definition: motivational primacy of the individual self, motivational primacy of the collective self, or contextual primacy? Journal of Personality and Social Psychology, 76, 5-18.

Grieve, P. G., \& Hogg, M. A. (1999). Subjective uncertainty and intergroup discrimination in the minimal group situation. Personality and Social Psychology Bulletin, 25, 926-940.

Guth, W., Schmittberger, R., \& Schwarz, B. (1982). An experimental analysis of ultimatum bargaining. Journal of Economic Behavior and Organization, 3, 367-388.

Hogg, M. A. (2000). Social identity and social comparison. In J. Suls, \& L. Wheeler (Eds.), Handbook of social comparison: Theory and research (pp. 401-421). New York: Kluwer Academic/Plenum Publishers.

Hogg, M. A. (2001). Self-categorization and subjective uncertainty resolution: cognitive and motivational facets of social identity and group membership. In J.P. Forgas, \& K. D. Williams (Eds.), Social mind: Cognitive and motivational aspects of interpersonal behavior (pp. 323-349). New York: Cambridge University Press.

Hogg, M. A., \& Abrams, D. (1990). Social motivation, self-esteem and social identity. In D. Abrams, \& M. A. Hogg (Eds.), Social identity theory: Constructive and critical advances (pp. 28-47). London: Harvester Wheatsheaf.

Hogg, M. A., Cooper-Shaw, L., \& Holzworth, D. W. (1993). Group prototypicality and depersonalized attraction in small interactive groups. Personality and Social Psychology Bulletin, 19, 452-465.

Hogg, M. A., \& Haines, S. C. (1996). Intergroup relations and group solidarity: effects of group identification and social beliefs on depersonalized attraction. Journal of Personality and Social Psychology, 70, 295-309.

Hogg, M. A., \& Mullin, B. A. (1999). Joining groups to reduce uncertainty: subjective uncertainty reduction and group identification. In D. Abrams, \& M. A. Hogg (Eds.), Social identity and social cognition (pp. 249-279). Oxford, UK: Blackwell.

Hsee, C. K., Loewenstein, G. F., Blount, S., \& Bazerman, M. H. (1999). Preference reversals between joint and separate evaluations of options: a review and theoretical analysis. Psychological Bulletin, 125, 576-590.

Loewenstein, G. F., Thompson, L., \& Bazerman, M. H. (1989). Social utility and decision making in interpersonal contexts. Journal of Personality and Social Psychology, 57, 426-441.

Messick, D. M., \& Sentis, K. P. (1985). Estimating social and nonsocial utility functions from ordinal data. European Journal of Social Psychology, 15, 389-399.

Mullin, B. A., \& Hogg, M. A. (1998). Diminensions of subjective uncertainty in social identification and minimal intergroup discrimination. British Journal of Social Psychology, 37, 345-365.

Oaker, G., \& Brown, R. (1986). Intergroup relations in a hospital setting: a further test of social identity theory. Human Relations, 39, 767-778.

Pillutla, M., \& Murnighan, K. (1996). Unfairness, anger, and spite: emotional rejections in ultimatum games. Organizational Behavior and Human Decision Processes, 68, 208-224.

Rabin, M. (1993). Incorporating fairness into game theory and economics. American Economic Review, 83, 12811302.

Rosenthal, R., \& Rosnow, R. (1991). Essentials of behavioral research: Methods and data analysis. New York: McGrawHill.

Roth, A. E. (1995). Bargaining experiments. In J. H. Kagel, \& A. E. Roth (Eds.), The handbook of experimental economics (pp. 253-348). Princeton, NJ: Princeton University Press.

Tajfel, H. (1981). Human groups and social categories: Studies in social psychology. Cambridge, UK: Cambridge University Press.

Turner, J. C. (1975). Social comparison and social identity: some prospects for intergroup behavior. European Journal of Social Psychology, 5, 5-34.

Turner, J. C. (1982). Towards a cognitive redefinition of the social group. In H. Tajfel (Ed.), Social identity and intergroup relations (pp. 15-40). Cambridge, UK: Cambridge University Press.

Turner, J. C., Brown, R. J., \& Tajfel, H. (1979). Social comparison and group interest in ingroup favoritism. European Journal of Social Psychology, 9, 187-204.

Turner, J. C., Hogg, M. A., Oakes, P. J., Reicher, S. D., \& Wetherell, M. S. (1987). Rediscovering the social group: A selfcategorization theory. Oxford: Basil Blackwell.

\section{Authors' biographies}

Stephen M. Garcia is an Assistant Professor of Public Policy and Faculty Associate of the Research Center for Group Dynamics at the University of Michigan. He was previously a research fellow at the Program on Negotiation at Harvard Law School. Stephen examines how self-categorization and social comparison processes impact choice behavior. He teaches negotiation at the Ford School of Public Policy and Ross School of Business. 
Avishalom Tor is an Assistant Professor of Law at the Haifa University School of Law in Israel. He has also been a postdoctoral fellow at the Olin Center for Law, Economics, and Business at Harvard Law School during much of his work on this paper. Avishalom's research is in behavioral law and economics. Recent publications include "Focusing failures in competitive environments," Journal of Behavioral Decision Making, 16, 353-374 (with Max Bazerman, 2003), and "The fable of entry," Michigan Law Review, 101, 482-568 (2002).

Max H. Bazerman is the Jesse Isidor Straus Professor of Business Administration at the Harvard Business School. Max's recent work includes Predictable surprises (2004, Harvard Business School Press, with Michael Watkins), You can't enlarge the pie: The psychology of ineffective government (2001, Basic Books, with J. Baron and K. Shonk), and Judgment in Managerial Decision Making (2005, Wiley, 6th ed.).

Dale T. Miller is the Morgridge Professor of Organizational Behavior at the Stanford Graduate School of Business and Professor of Psychology at Stanford University. His research explores the impact of social norms on behavior and the role that justice considerations play in individual and organizational decisions.

Authors' addresses

Stephen M. Garcia, University of Michigan, Gerald R. Ford School of Public Policy, Ann Arbor, MI 48109-1220, USA.

Avishalom Tor, Haifa University Faculty of Law, Mount Carmel, Haifa 31905, Israel

Max H. Bazerman, Harvard Business School, Mellon Hall D3-7, Soldiers Field Road, Boston, MA 02163, USA.

Dale T. Miller, Stanford University, Graduate School of Business, Stanford, CA 94305, USA. 